\title{
-
}

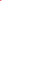

\section{Bacteria-Based Self-Healing Concrete: Towards Standardization}

\author{
Mors RM ${ }^{1,2}$ and Jonkers HIM ${ }^{1 *}$ \\ ${ }^{1}$ Department of Materials, Mechanics, Management \& Design (3MD), Netherlands \\ ${ }^{2}$ Green Basilisk, YES! Labs, Netherlands
}

\section{ISSN: 2576-8840}

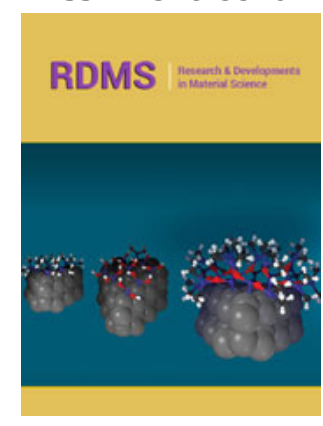

${ }^{* 1}$ Corresponding author: Jonkers HM, Department of Materials, Mechanics, Management \& Design (3MD), Section of Materials and Environment, Faculty of Civil Engineering \& Geosciences, Delft University of Technology, The Netherlands

Submission: 眥 March 13, 2019

Published: 眥 March 15, 2019

Volume 10 - Issue 2

How to cite this article: Mors R, Jonkers H. Bacteria-Based Self-Healing Concrete: Towards Standardization. Res Dev Material Sci. 10(2).RDMS.000732.2019. DOI: 10.31031/RDMS.2019.10.000732

Copyright@ Jonkers HM, This article is distributed under the terms of the Creative Commons Attribution 4.0 International License, which permits unrestricted use and redistribution provided that the original author and source are credited.

\begin{abstract}
Bacteria-based self-healing concrete is an innovative concrete that contains a self-healing agent that provides the material with enhanced crack-sealing performance. A specific type of this concrete, based on a healing agent composed of bacterial spores and lactate as carbon source, has been developed and applied by the Delft University of Technology for over ten years. The material potentially allows reduction of steel reinforcement used for crack width limitation in watertight constructions due to its autonomous crack-sealing potential of cracks up to $0.4 \mathrm{~mm}$ wide at a healing agent dosage quantity of $5 \mathrm{~kg} / \mathrm{m} 3$ concrete. This not only results in a reduction of costs but also in improvement of environmental performance (lower CO2 footprint) and ease of in situ casting due to reduction of steel in waterproof applications. However, according to the EN 1990 Eurocode (Basis of structural design), customary application of a novel type of concrete must be preceded by full scale demonstrators proving evidence for save and functional performance. In this contribution we portray two full scale demonstrator projects paving the way for application of bacteria-based self-healing concrete with reduced amount of reinforcement steel for watertight constructions.
\end{abstract}

\section{Introduction}

Cracking in concrete is an accepted phenomenon and does not have to lead to problems if it remains 'within limits'. These limits are laid down in codes describing what are acceptable crack widths for concrete structures in specific environments. Depending on the concrete mix composition and the amount of reinforcement applied, the construction can be designed in such a way that crack formation can remain limited. Nevertheless, we see in practice that crack formation can lead to unforeseen leakage problems or premature corrosion of the reinforcement requiring intervention. This often leads to unforeseen and high repair costs during or after finalization of the construction. The difference between anticipated (theoretical) crack formation and practical occurrence is mainly caused by a number of factors which are often beyond the control of the designer. A strategy to 'manage' the risk of unforeseen crack occurrence is to apply concrete with a high crack-sealing capacity: selfhealing concrete.

International research has been under way now for more than 10 years with the aim to develop concrete with increased self-healing ability. The Delft University of Technology is at the forefront of these developments and has developed a bio-based self-healing concrete technology that has been applied in practice. The technology is based on limestone-forming bacteria which are added, together with required bio-based nutrients, in form of a granular additive to the concrete mix.

\section{Autogenous healing of concrete}

Every type of concrete features a certain crack-sealing capacity. Documented research has shown that the capacity of this so-called 'autogenous' crack-healing relates particularly to the Portland clinker content and the particle size of the cement. The higher the dosage and the coarser the cement, the higher the crack-sealing capacity of the concrete [1-3]. However, these characteristics oppose developments that took place in the last decades towards low $\mathrm{CO}_{2}$ impact- and rapid strength developing concretes, typically featuring low clinker 
content- and fine grained cements. These cements, usually high in slag and / or fly ash content typically show less autogenous crackhealing capacity [4]. Latter research results therefore question whether current low clinker content binders still provide the same technical performance with respect to autogenous crack-healing potential as previous cements on which standards with respect to water tightness and durability aspects have been based. However, returning to high clinker cements appears from an environmental viewpoint undesirable and (relatively) low clinker containing concretes should therefore also feature a sufficient degree of crack-healing capacity. Challenge therefore is to achieve additional autonomous crack repair capacity while simultaneously keeping the $\mathrm{CO}_{2}$ impact of the concrete low.

\section{Crack repair by limestone-forming bacteria}

Of the large number of bacterial species that occur in nature, there are only a limited number that survive 'casting' in concrete. Such bacteria are not only used to highly alkaline conditions, as occurs in concrete, but also form 'spores'. These spores are resistant to many forms of stress such as high pressure, aggressive chemicals, dehydration and the like. Once suitable nutrients and water is available, they germinate and become active (vegetative) bacteria. Depending on the available nutrient type and environmental conditions (particularly the availability of calcium ions) they form limestone in addition to biomass (Figure 1).

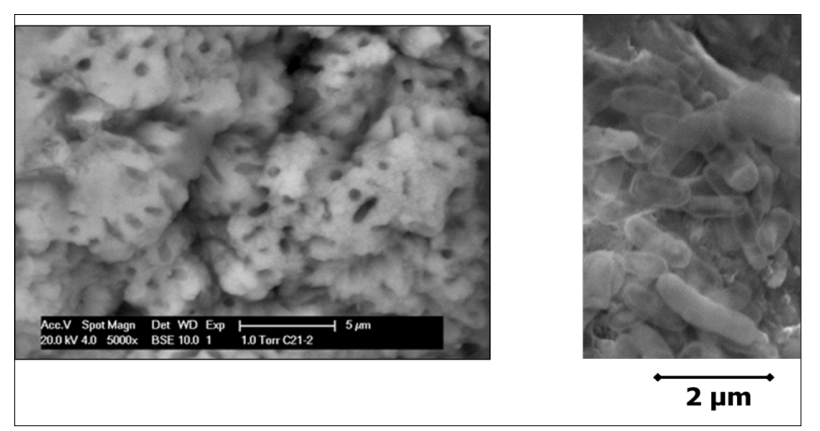

Figure 1: Environmental Scanning Electron Microscopic image of bacterial limestone (evidenced by bacterial imprints; left image) and light microscopic image of active (vegetative) alkaliresistant bacteria of the genus Bacillus (right image)

Limestone, or calcium carbonate, is a concrete compatible material that is perfectly suitable for sealing (waterproofing) cracks in concrete. Research has shown that lactate-based organic compounds are suitable nutrients for the bacteria and concrete compatible in the sense that they, within limits, do not negatively affect strength development of concrete, and as such lactate is also present in the declared list in the European norm on admixtures (EN 934 Admixtures for concrete, mortar and grout). Laboratory research has shown that, depending on the dosage of bacteria and lactate-based nutrients, cracks up to $1 \mathrm{~mm}$ width can be sealed autonomously. This requires a dosage of $15 \mathrm{~kg}$ of self-healing agent per $\mathrm{m}^{3}$ of concrete mix, while a dosage of $5 \mathrm{~kg} / \mathrm{m}^{3}$ leads to the autonomous waterproofing of $0.4 \mathrm{~mm}$ wide cracks (Figure 2).

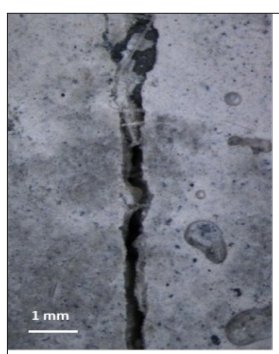

$\mathbf{t}=\mathbf{0}$

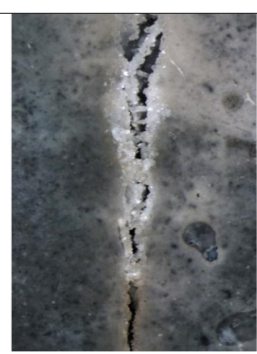

$\mathbf{t}=\mathbf{2 4 d}$

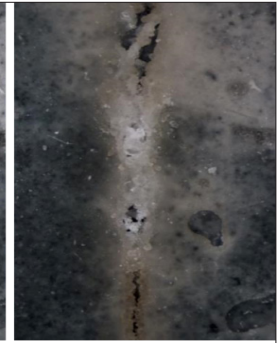

$\mathbf{t}=\mathbf{5 8 d}$
Figure 2: Self-healing of an $0.8-\mathrm{mm}$ wide crack in concrete at a dosage of $15 \mathrm{~kg}$ of self-healing agent per m3 takes up to two months.

Constructions in wet environments can specifically benefit from self-healing of cracks. Watertight constructions are commonly designed in such a way that only cracks of smaller than $0.1 \mathrm{~mm}$ width are allowed to occur. Such designs however require a lot of crack limiting reinforcement in addition to structural reinforcement steel. However, disadvantage of applying abundant steel is threefold: expensive, featuring high $\mathrm{CO}_{2}$ footprint, and finely meshed network hampers casting of the concrete mix. Instead, designing watertight constructions for marine- and freshwater applications, allowing crack widths of 0.2 and $0.4 \mathrm{~mm}$ respectively, would save substantial amounts of crack width limiting steel. This will result not only in more economic- and lower $\mathrm{CO}_{2}$ footprint structures but also in easier processability of the concrete mix. Latter will allow to work faster and will also lower the risk of forming gravel nests and hollow spaces in the structure. Water tightness of these structures will be delivered by autonomous crack-sealing of mixtures requiring a dosage of up to $5 \mathrm{~kg} / \mathrm{m}^{3}$ healing agent (Figure 3).

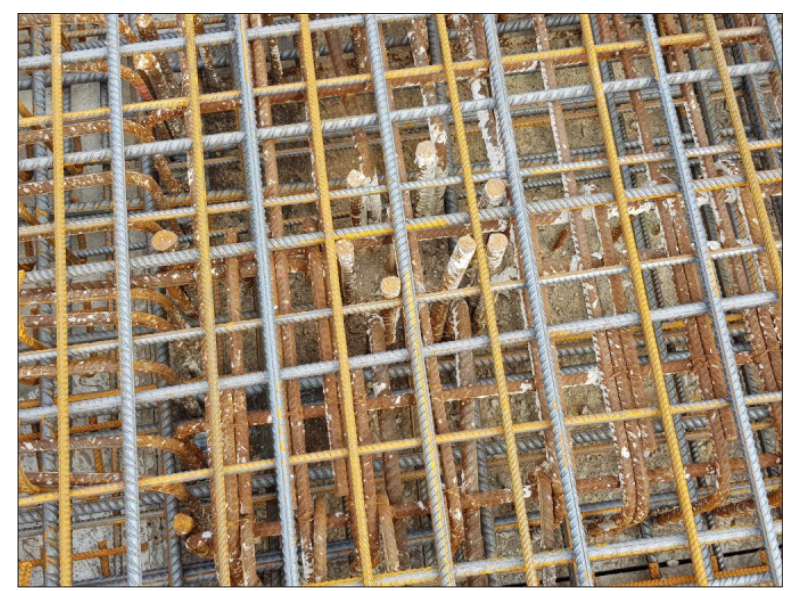

Figure 3: Picture of a finely meshed reinforcement network for watertight concrete constructions.

\section{Full scale self-healing concrete applications}

Precast application - wastewater purification tank: The first large-scale application of self-healing concrete was carried out in collaboration with the Water Boards Limburg (WBL), the Netherlands. The WBL's question was whether the application of self-healing concrete could lead to a reduction in cost-of-ownership, i.e. costs that are incurred over the entire life of a construction. In 
particular, maintenance and repair costs are high, the use of selfhealing concrete can reduce this by reducing the need for repair in combination with an extended service life of the construction. Therefore, it was decided to carry out a demonstrator project in the form of a wastewater treatment tank. The tank, consisting of prefab elements with dimensions of $7 \times 2.5 \times 0.15 \mathrm{~m}$ made by company BestCon, was installed in March 2016 at the test site of the WBL in Simpelveld and put into operation in August 2016 (Figure 4 photo tank under construction and tank in operation). Three out of the 15 applied elements were cast with a dosage of $10 \mathrm{~kg}$ healing agent per $\mathrm{m}^{3}$ concrete mix while the other 12 served as reference elements made of the same concrete mix featuring similar amount of steel reinforcement but without additional healing agent. To date, after being more than 2 years in operation, there is still no sign of cracking or other forms of degradation or damage in both selfhealing and reference type of elements. So far no negative effects of healing agent applications occurred, and ongoing monitoring of element performance in the coming years will show if application of self-healing technology for this type of application will be cost effective with respect to maintenance and service life.

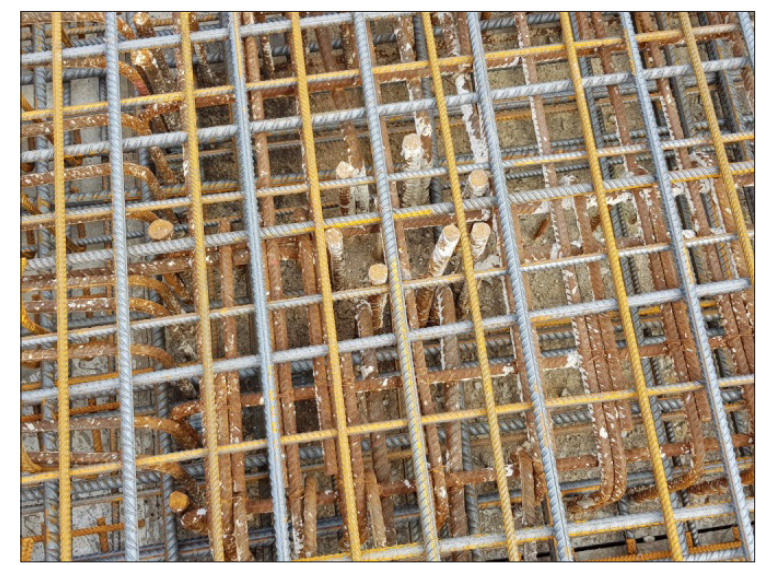

Figure 4: Prefabricated wastewater treatment tank under construction (left image) and in service (right image). Prefab elements bearing the triangular logo contain self-healing agent while the others do not.

In situ application - fire extinguishing water tank Hoogvliet, the Netherlands: In addition to prefab, full scale self-healing concrete has been applied in an in situ cast concrete construction (October 2017). It concerns a fire extinguishing water reservoir for the Port of Rotterdam Authority and was carried out by contractor BAM Infra. The reservoir is a rectangular concrete tank of 47 meters long, 5 meters high and 5.5 meters wide (Figure 4). To test the effectiveness of the self-healing agent added to the mixture, two walls of the tank (South and East facing) were made of self-healing concrete and the other two (North and West facing) of traditional concrete (same mix design without self-healing agent). The amount of applied steel reinforcement was equal in selfhealing and reference concrete and was in accordance with design criteria to allow only occurrence of cracks with a maximum width of $0.1 \mathrm{~mm}$. Because of strict water tightness constraints demanded by the owner, self-healing technology was used in this case as an additional precautionary measure to ensure water tightness of particularly the South facing wall (experiencing highest temperature fluctuations), avoiding injection repairs after casting and setting. The tank was filled with water in the summer of 2018 and only minor non-leaking hairline cracks were observed in the North facing wall (not containing healing agent). Like the prefabricated wastewater treatment tank also this in situ cast concrete reservoir will be monitored in the coming years to establish long-term water tightness performance.

\section{Cracks 'management' instead of crack prevention}

Waterproof structures require no risk of cracking or at least only very small cracks of $0.1 \mathrm{~mm}$ wide or preferably even smaller. The smaller the intended crack formation, the more crack width limiting reinforcement must be applied. This strategy, aiming for prevention of crack occurrence, thus requires a lot of reinforcement. As a result, the placement of in situ concrete will require extra attention in order to get the concrete mixture evenly distributed through the fine reinforcement meshes of the reinforcement, otherwise increasing the risk of obtaining implementation-related defects. Self-healing of cracks now presents an alternative strategy, i.e. 'management' of cracks instead of preventing their occurrence. A watertight construction design based on implementation of self-healing could therefore represent an alternative to one based on application of additional steel reinforcement. The concept of crack management will not only save material (costs) and concomitant lower $\mathrm{CO}_{2}$ impact but will also be beneficial in application because of coarser reinforcement network present, reducing the risk of execution related problems. Self-repair of 0.2$0.4 \mathrm{~mm}$ wide cracks will also ensure a waterproof construction, thus 'crack management' instead of 'crack prevention'. In the two full scale demonstrators described above, self-healing technology was applied as extra safety measure to guarantee water tightness. While no negative effects of addition of self-healing agent to the concrete mix and application was observed, the full capacity of the technology related to reinforcement reduction potential still needs to be resolved in another dedicated full-scale demonstrator project. This new demonstrator will, if successful, help to launch concrete self-healing technology as a serious crack management alternative to the current crack prevention strategy.

\section{References}

1. Edvardsen C (1999) Water permeability and autogenous healing of cracks in concrete. ACI Materials Journal 96(4): 448-454.

2. Neville AM (2002) Autogenous healing-A concrete miracle? Concrete Int 24(11): 76-82

3. Ter-Heide N, Schlangen E, van Breugel K (2005) Experimental study of crack healing of early age cracks. In Proceedings Knud Højgaard Conference on Advanced Cement-Based Materials, Technical University of Denmark, Kingdom of Denmark.

4. Palin D, Wiktor VAC, Jonkers HM (2015) Autogenous healing of marine exposed concrete: Characterization and quantification through visual crack closure. Cement and Concrete Research 73: 17-24. 